
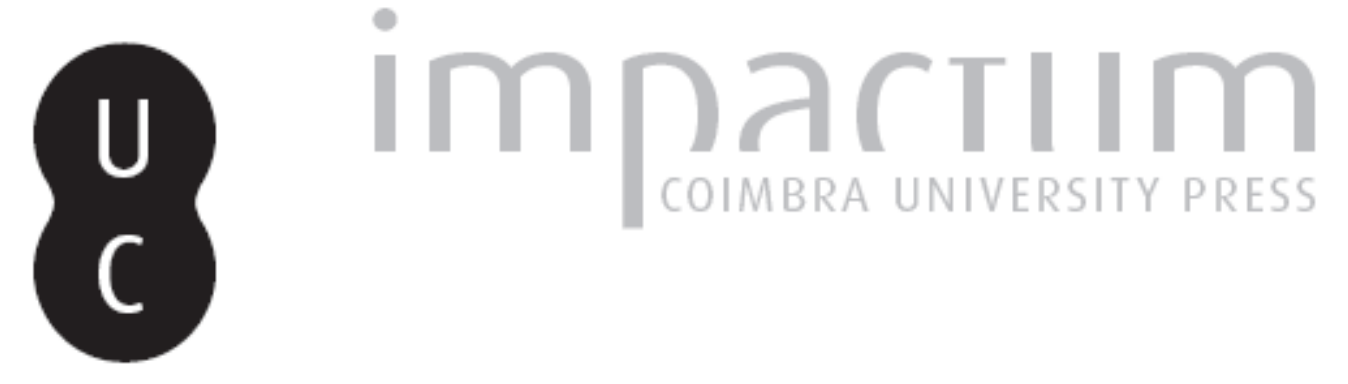

\title{
Antitradição e maravilhoso na poética do futurismo italiano
}

Autor(es): $\quad$ Vasconcelos, José Manuel de

Publicado por: Imprensa da Universidade de Coimbra

URL persistente:

URl:http://hdl.handle.net/10316.2/42571

DOI:

DOl:https://doi.org/10.14195/0870-8584_4_2

Accessed : $\quad$ 26-Apr-2023 13:12:55

A navegação consulta e descarregamento dos títulos inseridos nas Bibliotecas Digitais UC Digitalis, UC Pombalina e UC Impactum, pressupõem a aceitação plena e sem reservas dos Termos e Condições de Uso destas Bibliotecas Digitais, disponíveis em https://digitalis.uc.pt/pt-pt/termos.

Conforme exposto nos referidos Termos e Condições de Uso, o descarregamento de títulos de acesso restrito requer uma licença válida de autorização devendo o utilizador aceder ao(s) documento(s) a partir de um endereço de IP da instituição detentora da supramencionada licença.

Ao utilizador é apenas permitido o descarregamento para uso pessoal, pelo que o emprego do(s) título(s) descarregado(s) para outro fim, designadamente comercial, carece de autorização do respetivo autor ou editor da obra.

Na medida em que todas as obras da UC Digitalis se encontram protegidas pelo Código do Direito de Autor e Direitos Conexos e demais legislação aplicável, toda a cópia, parcial ou total, deste documento, nos casos em que é legalmente admitida, deverá conter ou fazer-se acompanhar por este aviso.

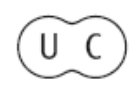




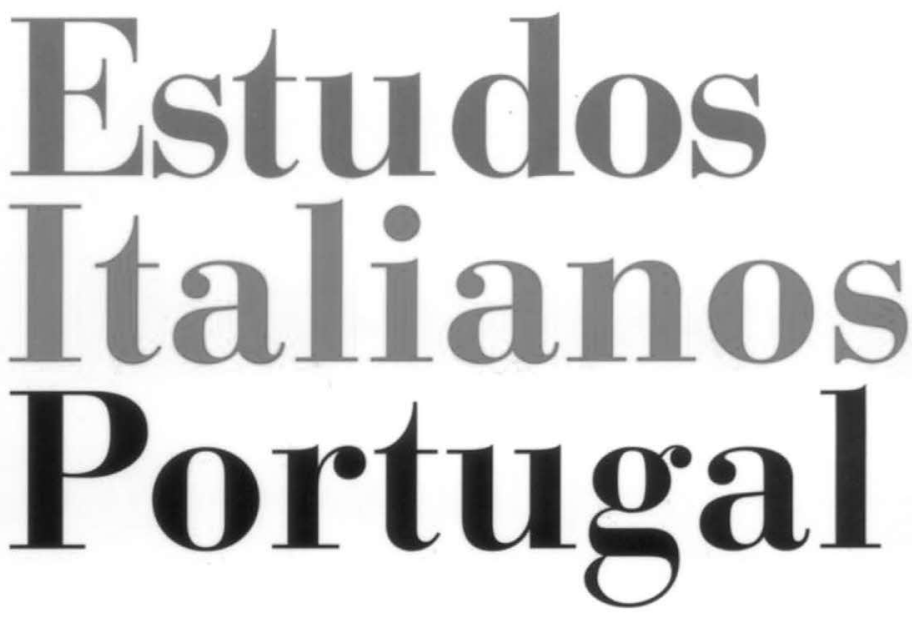

Instituto

Italiano

de Cultura

de Lisboa

Nova Série

$\mathbf{N}^{\mathbf{0}} 4$.

2009 


\section{ANTITRADIÇÃO E MARAVILHOSO \\ NA POÉTICA DO FUTURISMO ITALIANO}

José Manuel de Vasconcelos ${ }^{\star}$

O Futurismo italiano nasceu formalmente em 20 de Fevereiro de 1909, sob o signo da França. Marinetti publicou o Manifesto de fundação do movimento em Paris, no Le Fígaro, certamente por razões que se prendiam com a sua própria ligação a este país (vivera na capital francesa entre 1893 e 1896), mas, sobretudo porque Paris era, na época, a capital cultural do mundo, e o Le Fígaro um dos jornais de maior circulação da Europa. Estavam assim garantidas as condições de grande divulgação daquela primeira manifestação de vontade do novo movimento, de tal modo que, quando o Manifesto foi publicado em Itália, no número de Fevereiro/Março desse ano, da revista Poesia, a celeuma estava já em marcha acelerada. Por outro lado - o que também muito ajudava -, certo pensamento de expressão francesa, estava muito presente no "grito" inicial do futurismo: autores como Émile Zola, Georges Sorel, Maxime du Camp, Michelet, Paul Adam, Gustave Kahn, Mallarmé, Émile Verhaeren, Jules Romains e Henri Bergson constituíram

* José Manuel de Vasconcelos nasceu em Lisboa, e exerce a advocacia nesta cidade. Poeta, ensaísta e tradutor, tem vários livros publicados e colaboração nas principais revistas e jornais culturais da actualidade, encontrando-se representado em várias antologias. Organizou, traduziu e prefaciou uma Antologia do Futurismo Italiano, cuja reedição está no prelo. No domínio italiano, traduziu ainda Eugénio Montale e Umberto Saba. 
antecedentes parcelares das formulações globalizantes e radicais dos Futuristas. Acresce que em França tiveram lugar as mais importantes manifestações criativas do simbolismo, e é sabida a importância que determinados aspectos deste movimento tiveram na formação inicial do fundador do futurismo. O jovem Marinetti conheceu em França os princípios do verslibrisme; conviveu com o círculo do jornal La Plume, onde pontificavam figuras como Rémy de Gourmont, Léon Deschamps e, sobretudo Alfred Jarry cujas ousadas ideias sobre teatro parecem ter influenciado bastante o autor de Le Roi Bombance, peça que, curiosamente, foi estreada dois meses depois da publicação do primeiro Manifesto, no Théatre de L'Oeuvre, tornado famoso pela estreia de Le Roi Ubu, do famoso "pai" da Patafísica.

Claro que o futurismo italiano foi igualmente eco de muitos outros autores, cuja presença tem vindo a ser evidenciada, podendo chegar-se mesmo à conclusão de que o que o que se diz no Manifesto de 1909, consubstancia uma reunião de motivos de muitos outros escritores, sobretudo franceses, italianos e alemães. O próprio Marinetti expressou em várias circunstâncias a sua admiração por autores do passado, de que a título de exemplo referirei Walt Whitman, indiscutivelmente um "precursor" do futurismo, pela sua ideia de "existência multiplicada", com origem no mundo moderno e na presença nascente da maquinaria. Mas o certo é que é no confortável seio fin-de-siècle da cultura francesa que o futurismo é incubado, e não será desprezível lembrar que a já referida revista italiana Poesia, indissociável do movimento futurista, divulgou em Itália nomes como Baudelaire, Rimbaud, Verlaine, Mallarmé, Herédia, Paul Fort, Laforgue, etc. Bruno Romani, no seu livro Dal simbolismo al futurismo, publicado em 1969, afirma a este respeito que: "[...] o futurismo nasceu como um movimento francês, ainda que posteriormente tenha sido transplantado para a Itália, onde encon- 
trou um terreno mais propício às suas extravagâncias e às suas violências provincianas $[\ldots]$ ". ${ }^{1}$

Aparecer como um autor de expressão francesa, só poderia dar créditos a Marinetti, sobretudo fora de França, e o lançamento do movimento num local cosmopolita era um valor seguro, pela abertura e acolhimento que garantia. A pátria de Baudelaire, o poeta da "Fourmillante cité, pleine de rêves", (a cidade moderna com os seus movimentos caóticos, outro motivo forte do Futurismo), era sem dúvida a melhor tribuna para lançar as bases de um movimento que se queria realmente interventivo e contagiante. Mas tudo o que se acaba de dizer não pretende escamotear a evidência das muitas influências italianas, presentes nos manifestos e nos diversos textos criativos dos futuristas, como as de D’Annunzio, Papini, Prezzolini, Mário Morasso ou até, recuando bastante, do próprio Macchiavelli, na medida em que este autor defendeu a libertação da arte relativamente ao artificialismo académico, valorizando a impressão directa da realidade. E nas artes plásticas, será de referir a importância que tiveram o Divisionismo, um escultor como Medardo Rosso, a Escola de Posilippo e os Macchiaioli. Falando da cultura alemã, não deixarei de referir um nome que para os futuristas se apresentou sempre com um sabor agridoce: Nietzsche, cujo pensamento, embora em muitos aspectos se distinga do Futurismo, deixou sem dúvida marcas fundamentais em muitas teses do movimento: o seu amoralismo, a sua negação do passado e a sua confiança no porvir, o seu desprezo pela igualdade dos homens e, sobretudo a criação da figura do Super-Homem, que nos Futuristas assume os contornos artificiais do homem mecânico com partes substituíveis.

As concepções e teses dos Manifestos Futuristas não são pois em si mesmas inteiramente originais, o que é novo é o facto de muitas ideias que tinham sido defendidas por diver-

${ }^{1}$ Bruno Romani, Dal simbolismo al futurismo, Firenze, Sandrom, 1969, pp. 7-8. 
sos autores, e em diferentes contextos e épocas, serem apresentadas com uma unidade programática praticamente inédita até então, com o objectivo de agitarem as pessoas e agirem de facto sobre a realidade artística e cultural, mas também sobre a realidade económica e política, e, sobretudo sobre as mentalidades, incitando-as à polémica, à agitação desenfreada e convidando-as a construir a sua própria liberdade. E tudo isto, embora dito e defendido de maneira muito original e ousada, resumia o que de mais evidente e duradouro a história do pensamento, desde finais do século XVIII e sobretudo durante todo o século XIX, tinha trazido de novo: a consciência de necessidade e inevitabilidade de mudanças radicais, a convicção progressiva de que a acção para ser eficaz tinha de ser antecedida pela destruição. Nada ficou de fora da voragem futurista, desde a literatura e das artes plásticas, ao teatro, à música e às artes visuais, desde a política à pedagogia, à moda, à decoração, às técnicas, à matemática e à própria cozinha (como é sabido, encontra-se publicado um número significativo de receitas de cozinha futuristas, todas muito variadas, mas com uma constante deplorável: o facto de não ser comestível o produto de nenhuma delas.) Para todos estes sectores de actividade os futuristas apresentaram programas, manifestos, conselhos, pontos de vista, ditames; em todos se imiscuíram na teoria e na prática; em relação a todos eles procuraram agitar as consciências. O "núcleo duro" do Movimento, no período de ouro da sua actuação, os anos imediatamente a seguir ao ano do Manifesto de 1909, desdobrava-se em actividades, intervindo permanentemente na vida italiana e europeia. Marinetti, chegou, pela sua imparável e frenética acção, a ser chamado "A cafeína da Europa”. O Futurismo aparecia em cena como o primeiro movimento portador de uma verdadeira "ideologia global".

Sediado em Milão, o Futurismo pretendeu assumir-se como um fenómeno do norte de Itália, colocou-se do lado 
do país moderno, industrial e activista contra a Itália do passado, pitoresca, paralizadamente católica, ruralizante e paisagista; afastou o país do classicismo, da "arte eterna" e dos mestres idolatrados e preservados com subserviência. Milão, por outro lado, embora fosse a cidade mais moderna de Itália, não fizera acompanhar o seu desenvolvimento económico e industrial, de uma autêntica renovação cultural, e os Futuristas entendiam que era preciso fazê-lo. Para isso, pretendia-se um contacto directo com as pessoas, criar um público, organizar a multidão, obrigar a escolher e a tomar partido, espicaçar a inércia, o habitual adormecimento nos ópios passadistas. Exemplo disso são as famosas Serate Futuriste, em que são criadas situações de confronto e provocação no público, apresentadas dramatizações cheias de agressividade, e teatralização das ideias proclamadas nos manifestos. Estes serões ou noitadas criaram um estilo, um modo de actuação que marcou todo o teatro-performance contemporâneo, e que está na base de manifestações como os happenings. Pense-se por exemplo o que grupos como o catalão La Fura dals Baus deve aos futuristas. Para tudo isso, o movimento precisava de ter, e tinha, um chefe, uma organização muito forte, com regras de ferro e obediência indiscutível. Organizavam-se intervenções públicas, publicava-se, distribuíam-se, a maior parte das vezes gratuitamente, publicações, folhas, revistas, proclamações. Organizavam-se espectáculos, recitais, intervenções diversas, definiam-se estratégias de propaganda, estabeleciam-se ortodoxias, definiam-se hierarquias. O movimento consciente do seu poder de intervenção e de sugestão, da importância cultural, social e política que tinha na vida italiana, funcionava como uma estrutura produtiva ou um partido político, a que não faltaram as contradições e polémicas internas, e mesmo as rupturas (Veja-se o caso da demarcação e afastamento de Papini e Soffici, após a publicação em 1914 do famoso artigo na revista Lacerba). Elémire Zolla 
referindo-se a este pendor organizativo de alguns movimentos da vanguarda europeia, de que o futurismo é o primeiro e certamente o mais extremo exemplo, mas que se pode encontrar também em movimentos como o Dadaísmo e o Surrealismo usou a sugestiva expressão "a vanguarda como empresa".

A visão futurista, como sucede com todas as utopias, cede a um maravilhamento: o do futuro impecável, expurgado de todas as escórias do passado e a funcionar de forma exemplar. No centro desse reino maravilhoso está a máquina, símbolo maior da vasta alegoria futurista, surgindo logo no manifesto fundador sob a forma do automóvel de corrida "com o seu cofre enfeitado por grossos tubos semelhantes a serpentes de hálito explosivo". O movimento mecânico, a velocidade, o fluxo esmagador da multidão, espécie de actualização do unanimismo de Jules Romains, a luta incessante, a veemência que pretende encarnar o absoluto, a embriaguês da mecanização, tudo isso compõe o cenário maravilhoso da paisagem futurista que cintila num futuro mítico, mas sem esquecer a forja convulsiva do presente, a grande oficina onde numa amálgama fantástica se destrói o que representa o passado e se produzem os germes do futuro redentor, o que significa no fundo encarar o presente como único e verdadeiro tempo da acção, renovando a heraclitiana ideia de que o único Eterno é o Presente no qual nascem os grandes imperativos, e também na negação do espaço vindo do passado: o espaço compartimentado, definido, fechado, que é substituído pelo poder da simultaneidade tornada possível pelo aparecimento do automóvel, do aeroplano, da locomotiva, das máquinas em geral. O Futurismo aspira assim à criação de um "homem novo", de um homo faber sobreposto ao homo sapiens, cavalgando nas conquistas técnicas e nas descobertas científicas do presente, encaradas como uma espécie de novo exotismo, rumo a um futuro indefinido, mas fortemente desejado, no qual se acredita sem reservas e onde, no limite, pela subs- 
tituição progressiva do natural pelo artificial, o homem se iria até libertando da própria morte. Talvez por isso não seja exagerada a opinião de Glauco Viazzi de que, pela sua estrutura, veemência e objectivos o Manifesto de Marinetti de 1909, tinha como arquétipo o Manifesto Comunista de Marx e Engels, mergulhando à sua maneira nas marés utopistas cuja força foi tão evidente no século XIX. Se a ideia de futuro está contida na própria palavra com que o movimento finalmente se baptizou (no início Marinetti hesitou entre os nomes Dinamismo e Electricismo, havendo quem acredite que a palavra Futurismo acabou por ser escolhida, não só por remeter para a ideia de Futuro, mas também por conter as letras F e T iniciais dos dois nomes de Marinetti, Filippo Tommaso) é principalmente do Presente que o movimento nos fala, naturalmente porque é nele que reside o verdadeiro tempo da revolução, ideia central que anima o ímpeto futurista inicial, pois o Presente, associado à Velocidade, aboliria as tradicionais barreiras do tempo e do espaço, já que a velocidade é o presente a cavalo de si próprio, a anulação da sucessividade, fábula do eterno, inscrição da história no círculo da utopia.

A civilização mecânica sobrepõe-se pois ao homem, a maternidade deste passa a ser a oficina, e o homem será engendrado pela própria máquina. $\mathrm{O}$ Futurismo é assim o reverso de qualquer ideia de humanismo (este um dos pontos de encontro com o pensamento de Nietzsche). A mecanização é apresentada como um axioma, algo do qual se parte num furor apologético, sem necessidade de quaisquer argumentos demonstrativos de natureza racional, o que não admira, num movimento que desprezava a inteligência racional, e a substituía pela intuição, que considerava característica das "raças latinas". Ou seja, fazendo parte do novo mundo maravilhoso instituído pela crença futurista, a máquina e a civilização que dela decorre, não carecem de qualquer outra legitimação, que não seja o simples facto de 
não existirem no passado e de, portanto, se inscreverem nessa atitude radical e genérica de negação.

A ideia e o culto do futuro apresenta-se nos Manifestos de maneira panfletária, sem que sejam desenvolvidos argumentos ou apresentadas razões. A lógica é postergada, e o discurso flui em repelões sensacionalistas, numa retórica provocatória e violenta, procurando fazer tábua rasa de todo o passado, tornando-o uma espécie de monstro a abater. Os Futuristas da primeira fase comportam-se como adolescentes em reacção à autoridade paterna, fundada no conservadorismo e na repetição, na idolatria embasbacada dos valores ditos eternos, rejeitando a prática domesticada de gerações de jovens que se tornavam adultos demasiado cedo e que, no fundo, não sabiam viver a alegria e a frescura da sua juventude, não passando de tristes adultos em potência. $\mathrm{O}$ discurso futurista tem um carácter dirigido: pretende actuar imediata e directamente, atingindo objectivos visíveis. A construção do futuro far-se-ia a partir de um presente completamente expurgado de todos os vestígios malsãos, e a partir daquilo a que poderíamos chamar os novos elementos da construção futura. Mas a demolição não se faria apenas na realidade exterior; o espírito humano teria de ficar imbuído de uma fé irracional nessa dimensão do desconhecido que um presente apagado de referências inevitavelmente traria. A ideia de progresso nas palavras futuristas baila como um eco do além, como uma emanação quase arquetipal, inconsciente, brilhando a partir do que se poderia chamar uma treva brilhante. Esta espécie de claro-escuro do discurso futurista faz lembrar por vezes o sentido do irrequieto, o furor perspectivado que caracteriza a estética barroca. Como disse Wölfflin, o Barroco não quer dar testemunho de uma existência satisfeita e em calma, mas de um estado de excitação, de turbulência. Algo de semelhante se passa com o Futurismo. A utilização permanente da antítese, da hipérbole, de metáforas que, se por um lado traduzem a metamorfose, por outro chegam a cair na crista- 
lização, e até na hipostasia, o recurso a um dramatismo declamante, de onde se escapa a volúpia e o frenesim lúdico, lembram a atracção para o instante, para o fugidio, para a sensorialização das emoções que caracterizam o barroco. O maravilhoso barroco parece assim provocar ecos no Futurismo, como de resto em algumas vanguardas contemporâneas. Os mitos e a sua teatralização, o corpo mecanizado, tendo por fundo uma espécie de irracional fogo-de-artificio estabelecem paralelos que, carecendo de melhor investigação e aprofundamento, não me parecem despiciendos. De todos os mitos, o mito do progresso ocupa um lugar fundamental, que se transportou até aos nossos dias. Incondicional é a passagem pela porta que conduz a essa aventura no desconhecido. Tudo isto se entende numa Itália a precisar de se industrializar urgentemente, com um preocupante excesso demográfico a exigir espaço e novas condições. Marinetti sabe bem que o seu movimento tem objectivos globais. Não se fica pelas artes, pela cultura, quer ir mais longe, forjando razões para as grandes opções políticas nacionais, nomeadamente a guerra, o irredentismo e o expansionismo, ancorando-os em motivos aparentemente idealistas e até poéticos como a ânsia de originalidade, "a vida aventurosa, enérgica e quotidianamente heróica". Apresentando o movimento futurista como um modo de prolongar o Risorgimento, e a si próprio como um continuador de Garibaldi, Marinetti pretende chegar rapidamente à acção política, transplantando para esse campo os princípios e valores que no início pareciam estar confinados apenas às actividades artísticas e intelectuais. Numa estranha e frenética mistura de nacionalismo e anarquismo que com o tempo, deixa apagar os fogachos libertários e se transforma num patriotismo cego defendendo a voragem imperialista, e marchando ao lado do fascismo, o futurismo defende "o orgulho, a energia e a expansão nacional", diz querer acabar com as múmias e libertar o país de toda "a vileza pacifista". 
A visão da guerra como "Futurismo intensificado", o malthusianismo subjacente à sua caracterização como único modo eficaz de limpeza das escórias do mundo, conduzindo a uma negação do passado e, portanto, da história, assente numa mística vitalista, a utopia de uma última guerra de objectivos reordenadores e equilibrantes, que aproxima o movimento das aventuras totalitárias da primeira metade do século passado, e das duas guerras mundiais, fazem também parte daquele sopro utópico que tende para a crença num maravilhoso que subjaz às diversas manifestações do Futurismo. Boccioni fala da guerra como "coisa bela, maravilhosa, terrível”, Marinetti vê nela uma espécie de complemento das imperfeições naturais. A guerra vem associada ao prazer, a uma espécie de gozo supremo, de manifestação de sensualidade e de vitalismo, como se vê das palavras de Valentine de Saint-Point, no seu famoso Manifesto Futurista da Luxúria, cuja data, 1913, deixava sentir já as explosões e os gazes do conflito terrível que se aproximava: "A luxúria triunfa porque é a exaltação do gozo que impele o ser para além de si mesmo, a alegria da posse e da dominação, a perpétua vitória da qual renasce a perpétua batalha, a embriaguês de conquista mais inebriante e mais segura". ${ }^{2}$ A arte estaria ao serviço do reino tecnológico que por si mesmo constitui uma progressiva negação da natureza, a guerra garantiria, para além dos seus objectivos higiénicos, o dinamismo, o erotismo e a sensualidade de que o homem carece para que se exprima livremente o seu impulso vital. Ambos convergiriam para a realização de um mundo em que o artificial seria a maravilhosa expressão da vitória final sobre as limitações da natureza e da história. 